\title{
APLIKASI SISTEM PENYEDIAAN AIR BERSIH BERBASIS MASYARAKAT DI PULAU PANDANGAN, KABUPATEN PANGKAJENE, SULAWESI SELATAN
}

\author{
System Application Water Supply Community-Based \\ in Pandangan Island, Pangkajene regency, South Sulawesi \\ Oleh : \\ Arie Herlambang \\ Pusat Tekologi Lingkungan, BPPT
}

\begin{abstract}
Abstrak
Pangkajene kepulauan, adalah gugusan kepulauan yang terdiri dari 117 pulau yang tersebar di Pantai Barat Kabupaten Pangkajene. Pulau-pulau tersebut dihuni oleh penduduk berkisar 10 sd 250 kepala keluarga. Sebagian besar penduduk bermata pencaharian sebagai nelayan. Untuk menunjang kebutuhan pokok sehari-hari masih dipasok dari daratan, termasuk kebutuhan air bersih. Kebutuhan air bersih masyarakat selama ini banyak tergantung dari air hujan yang ditampung atau dari air tanah dangkal. Sejalan dengan pertumbuhan penduduk, kebutuhan air meningkat, sehingga sering terjadi kesulitan air, terutama pada musim kemarau. Teknologi pengolahan air laut dengan sistem osmosa balik (reverse osmosis) merupakan salah satu alternatif untuk penyelesaian kekurangan air di pulau, namun karena jumlah pulaunya banyak, maka akan sulit untuk dipenuhi kebutuhan airnya dalam waktu singkat. Oleh karena di pilih tiga pulau yang posisinya ditengah (Pulau Saroppe Cakdi, Pulau Sanane dan Pulau Pandangan) sebagai pusat distribusi. Kapasitas yang terpasang untuk masing-masing pulau adalah $10 \mathrm{~m}^{3} /$ hari, yang dapat melayani untuk kebutuhan air minum seribu orang. Teknologi Pengolahan air dengan osmosa balik terdiri dari pengolahan awal berupa multi media filter yang terdiri dari pasir silika, zeolit, dan karbon aktif, dilanjutkan dengan kartride filter dan membran osmosa balik. Pembangunan unit pengolah air ini melibatkan masyarakat sejak mulai survei penentuan lokasi, konstruksi, pelatihan dan pengoperasian awal. Air yang sudah diolah dapat langsung diminum untuk keperluan seharihari, oleh karena itu untuk menunjang operasional air tersebut dijual kepada masyarakat untuk pengganti uang operasional. Biaya terbesar yang dibutuhkan untuk memproduksi air adalah biaya bahan bakar. Dengan mengelola hasil penjualan air diharapkan biaya operasional dapat terpenuhi dan masyarakat mendapatkan air minum dengan harga terjangkau.
\end{abstract}

Kata Kunci : air minum, reverse osmosis, pelibatan masyarakat.

\begin{abstract}
Pangkajene archipelago, is archipelago comprising 117 islands scattered in the West Coast District Pangkajene. The islands were inhabited by populations ranging from 10 to 250 heads of families. Most of the population livelihood as a fisherman. To support the daily basic needs are still supplied from the mainland, including the need for clean water. Community water needs during this time a lot depends on rain water that collected or from shallow groundwater. In line with population growth, water demand increases, so frequent water shortages, especially during the dry season. Sea water treatment technology with reverse osmosis systems is an alternative to the settlement of water shortage on the island, but because the number of islands many, it will be difficult to meet the needs of water in a short time. Therefore chosen the middle position of the three islands (Cakdi Saroppe Island, Island and Island Sanane view) as a distribution center. Installed capacity for each of the islands is $10 \mathrm{m3} /$ day, which can serve to the needs of drinking water a thousand people. Water treatment technology with reverse osmosis pretreatment consist of the form of multi-media filter consisting of silica sand, zeolite, and activated carbon, followed by cartride filter and a reverse osmosis membrane. Construction of the water treatment unit involves people since it began surveying best location, construction, training and initial operation. Water that has been processed can drink for everyday purposes, therefore, to support the operations of the water is sold to the public for replacement of operational money. The biggest cost needed to produce water is the cost of fuel. By managing the sale of water expected operating costs can be met and comunity get drinking water at an affordable price.
\end{abstract}

Keyword : dringking water, reverse osmosis, society engangement. 


\section{PENDAHULUAN}

Pengadaan air bersih di Indonesia khususnya untuk skala besar masih terpusat di daerah perkotaan yang dikelola oleh Perusahaan Air Minum (PAM). Untuk skala pedesaan yang lebih kecil, sejauh ini baru mencapai beberapa Ibu Kota Kecamatan. Secara nasional jumlah penyediaan air minum masih jauh dari mencukupi. Penduduk yang terlayani baru mencapai 19 \%. Untuk daerah yang belum mendapatkan pelayanan air bersih dari PAM, umumnya mereka menggunakan air tanah (sumur), air sungai, air hujan, mata air dan sumber air lainnya.

Banyak wilayah di Indonesia yang kualitas sumber air permukaan ataupun air tanahnya tidak memenuhi syarat untuk digunakan sebagai air minum. Desa-desa di beberapa kecamatan di Kabupaten Pangkep, Sulawesi Selatan merupakan contoh lokasi yang jelas tentang adanya masalah sulitnya mengatasi pemenuhan kebutuhan air bersih atau air minum. Desa-desa tersebut terletak di daerah pinggir pantai dengan daratan yang telah terintrusi air laut, sehingga masyarakat desa tidak mempunyai sumber air untuk pemenuhan kebutuhan air bersihnya.

Kabupaten Pangkajene Kepulauan atau biasa disingkat dengan Pangkep, terletak sebelah utara kota Makasar, dapat ditempuh dengan kendaraan dalam waktu satu jam dari Bandara Hasanudin, Maros. Kabupaten Pangkep terdiri dari daerah daratan dan kepulauan. Jumlah Pulau yang ada di Kepulauan Pangkajene adalah sekitar 117 pulau.

Air bersih merupakan barang langka di pulaupulau kecil, terutama yang penduduknya cukup rapat. Untuk mendapatkan air bersih masyarakat umumnya menggali sumur dangkal, namun pada musim kemarau berubah menjadi asin dan pada pemukiman yang padat kualitasnya menurun dari tahun ke tahun. Pada beberapa tempat dijumpai juga bantuan Pemerintah yang berupa Penampungan Air Hujan (PAH) dengan ukuran $10 \mathrm{~m}^{3}$, namun tidak terawat dan bocor. Usaha pemda mengadakan air bersih juga pernah mengadakan peralatan desalinasi dengan sistem boiler, namun gagal dan tidak pernah berjalan baik. Pernah pula dilakukan upaya untuk memasok air bersih dengan menggunakan perahu tongkang, namun ternyata biaya operasional tinggi dan akhirnya tongkang terbengkalai dan tidak dapat beroperasi lagi.

Dari berbagai upaya di atas, PAH masih layak utnuk dilanjutkan, hanya memerlukan perawatan kecil dan tidak mahal. Untuk menambah kesadaran masyarakat untuk memelihara diperlukan penguatan pemahaman melalui penyuluhan, Untuk satu unit PAH dengan kapasitas $5 \mathrm{~m}^{3}$ dapat menopang kebutuhan air minum satu keluarga selama dua bulan. Untuk musim kemarau panjang terkadang sampai 4 bulan, oleh karena itu diperlukan upaya untuk mengatasi kekurangan air pada musim kemarau panjang, dengan sistem yang hanya beroperasi pada musim kemarau.

Masyarakat Kepulauan Pangkajene, mempunyai sifat gotong royong yang kuat, terutama menyangkut keagamaan. Sebagian besar penduduknya beragama Islam, kondisi bisa dilihat dari bangunan mesjid yang besar, bagus dan megah dan banyak dijumpai di pulau-pulau yang banyak penduduknya. Sifat gotong royong tersebut juga sangat kuat ditunjukkan ketika pemasangan instalasi air bersih. Peran pemimpin cukup menonjol dan pendapatnya sangat diperhatikan oleh lingkungannya.

Bermodal pada sifat gotong royong dan kuatnya kepemimpinan, maka sistem pengelolaan air yang ada perlu dikembangkan dan dipercayakan untuk dikelola oleh masyarakat sendiri. Selama ini masalah air bersih di daerah selalu menjadi tanggung jawab PDAM atau dinas pekerjaan umum, namun karena jarak pulau yang jauh dari daratan dan terkadang musim yang tidak bersahabat, maka air bersih di pulau-pulau kurang diperhatikan. Oleh karena itu pengelolaan air bersih berbasis masyarakat perlu dikembangkan agar masyarakat mandiri dan berdaya dalam pengadaan air bersih terutama pada musim kemarau panjang. Jika air bersih tersedia, waktu atau uang yang selama ini tersita untuk mendapatkan air bersih dapat dimanfaatkan untuk keperluan lain dan lebih produktif dan dapat membuat masyarakat lebih sejahtera.

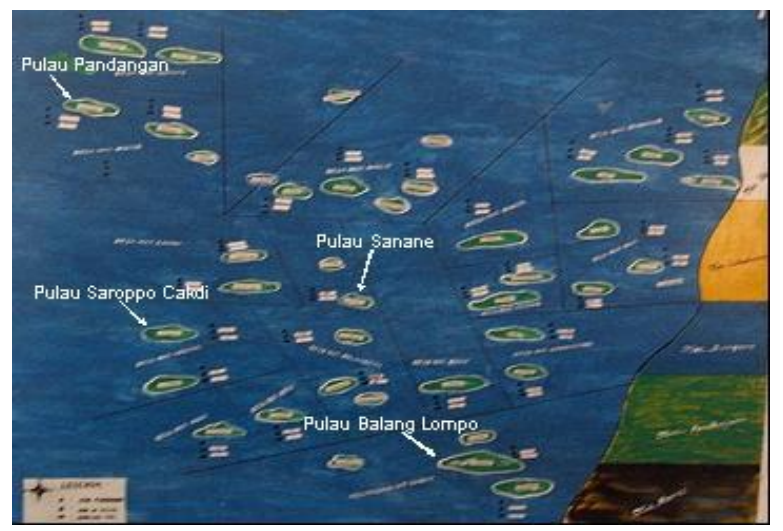

Gambar 1 : epaulauan Pangkajene Kepulauan, sebelah barat Kabupaten Pangkaje, Utara Makasar, Sulawesi Selatan.

Untuk mengatasi permasalahan di atas dibutuhkan penerapan teknologi pengolahan air yang sesuai (tepat guna). Berdasarkan permasalahan yang ada ternyata sumber air baku yang baik, yaitu yang tawar, tidak mungkin dijumpai di daerah desa-desa 
tersebut, sehingga jenis teknologi yang sesuai dengan kondisi sumber air baku adalah teknologi proses dengan sistem osmosa balik. Setiap penerapan teknologi, sekalipun yang sederhana, tetap memerlukan upaya pengkondisian masyarakat setempat. Oleh karena itu diperlukan upaya untuk peningkatan kualitas sumberdaya manusia dalam segi pemahaman iptek, khususnya dalam kaitannya dengan kondisi sosial, budaya dan tingkat ekonomi masyarakat dalam menerima transfer teknologi pengolahan air. Tujuan utama dari penerapan teknologi pengolahan air siap minum sistem reverse osmosis kapasitas $10 \mathrm{~m}^{3}$ /hari adalah memenuhi kebutuhan air minum / air tawar untuk daerahdaerah yang sulit air misalnya daerah di kawasan pesisir pantai dan pulau-pulau terpencil.

Secara kualitatif sasaran yang akan dicapai dengan penerapan teknologi pengolahan air payau dengan sistem osmosa balik ini adalah penguasaan teknologi proses pengolahan air payau bagi masyarakat pedesaan untuk mengatasi masalah kekurangan air bersih/minum, sehingga dengan demikian pemahaman iptek dalam masyarakat akan meningkat. Dengan tersedianya air minum bagi masyarakat, maka tingkat kesejahteraan masyarakat juga akan membaik. Secara kuantitatif sasaran yang akan dicapai dengan penerapan teknologi pengolahan air payau dengan sistem reverse omosis adalah adanya sarana penunjang utama, yaitu unit pengolahan air payau menjadi air siap minum dengan sistem reverse osmosis di Pulau Pandangan dengan kapasitas 10.000 liter/hari.

\section{TUJUAN}

Aplikasi teknologi pengolahan air laut sistem reverse osmosis kapasitas $10 \mathrm{~m}^{3} /$ hari untuk mengatasi kekurangan air di Kepulauan Pangkajene Kepulauan.

\section{RUANG LINGKUP}

Lingkup Kegiatan dalam instakasi pengolahan air minum dibagi menjadi 10 tahap kegiatan, mulai dari survei lokasi, sosialisasi kepada masyarakat, membuat desain, perakitan, pengiriman barang, instalasi, uji coba, pelatihan dan serah terima dan monitoring. Tahapan yang paling menentukan adalah penentuan lokasi, karena terkait sumber air baku dan kemudahan dalam pengiriman barang serta instalasi peralatan.

Tabel 1 : Lingkup Kegiatan Per Tahap.

\begin{tabular}{|c|l|}
\hline No. & Kegiatan \\
\hline 1 & $\begin{array}{l}\text { Survei lokasi dan kualitas air baku yang akan } \\
\text { digunakan sebagai sumber air baku. }\end{array}$ \\
\hline
\end{tabular}

\begin{tabular}{|c|l|}
\hline 2 & $\begin{array}{l}\text { Memberikan Penyuluhan pada masyarakat } \\
\text { desa terpilih. }\end{array}$ \\
\hline 3 & $\begin{array}{l}\text { Disain rancang bangun dan proses } \\
\text { pengolahan serta spesifikasi peralatan yang } \\
\text { digunakan untuk kapasitas } 10 \mathrm{~m}^{3} / \text { hari. }\end{array}$ \\
\hline 4 & $\begin{array}{l}\text { Pengadaan peralatan, pompa air baku, } \\
\text { pompa dosing, tangki kimia, static mixer dll. }\end{array}$ \\
\hline 5 & $\begin{array}{l}\text { Pengadaan peralatan tangki reaktor, } \\
\text { klarifier, Pompa air baku. Filter Multi Media, } \\
\text { Anti Scalant, Anti Biofouling. }\end{array}$ \\
\hline 6 & $\begin{array}{l}\text { Pengiriman alat ke lokasi. } \\
\text { Installing IPA-RO kapasitas 10.000 I /hari. } \\
\text { Satu unit IPA Air Payau 10.000 I / hari }\end{array}$ \\
\hline 8 & $\begin{array}{l}\text { Uji coba peralatan. Laporan Running Test } \\
\text { Unit IPA Arsinum }\end{array}$ \\
\hline 9 & $\begin{array}{l}\text { Pelatihan pengoperasian dan manajemen . } \\
\text { Peningkatan SDM untuk operator dan } \\
\text { manager Unit }\end{array}$ \\
\hline 10 & $\begin{array}{l}\text { Serah terima pengelolaan IPA Payau dan } \\
\text { Pembuatan laporan akhir. Laporan Akhir \& } \\
\text { Serah-Terima Unit IPA Payau }\end{array}$ \\
\hline
\end{tabular}

\section{METODOLOGI PENELITIAN}

\subsection{Survei Lapangan}

Survei ini dilakukan untuk mengetahui secara detail tentang keadaan di lapangan, khususnya mengenai jumlah penduduk yang akan dilayani, kualitas air tanah/sumur/permukaan, serta kondisi sosial masyarakatnya. Pada saat survei ini juga dilakukan sosialisasi mengenai teknologi pengolahan airnya.

Sebagian masyarakat masih menyangsi-kan keberhasilan teknologi ini, karena ada beberapa kegagalan yang pernah terjadi pada beberapa waktu sebelumya. Pada saat survei lapangan ini juga dilakukan observasi terhadap beberapa orang yang akan dilatih menjadi calon operator peralatan yang akan dipasang. Orang yang dicari adalah orang yang mampu mengoperasikan mesin diesel. Pada umumnya nelayan sudah terbiasa dengan mesin diesel, jadi tidak terlalu sulit mendapatkannya.

\subsection{Penentuan Lokasi}

Lokasi peralatan harus ditentukan sedemikian rupa agar didapatkan hasil yang memuaskan, baik ditinjau dari segi teknis maupun estetika. Sedapat mungkin lokasi ditentukan agar tidak terlalu jauh dari pemukiman masyarakat setempat. Untuk menerapkan teknologi baru di suatu tempat yang tergolong pedesaan haruslah dilakukan pengkondisian masyarakat setempat. Karena itu perlu dilakukan pemasyarakatan program kegiatan melalui penyuluhan - penyuluhan kepada penduduk, khususnya di Pulau Pandangan. 


\subsection{Ketersediaan Bahan dan Peralatan}

Bahan dan peralatan yang diperlukan untuk pembangunan unit pengolahan air payau untuk air siap minum diharapkan dapat dengan mudah didapat di pasaran, sehingga dapat memberikan kemudahan dalam pengerjaan pembangunan dan biaya konstruksi dapat ditekan serendah mungkin.

\subsection{Rancangan dan Konstruksi}

Disain unit alat pengolah air payau dirancang berdasarkan jumlah dan kualitas air baku, kapasitas produksi serta sesuai dengan ketersediaan lahan dan biaya yang tersedia. Instalasi Pengolahan Air (IPA) tersebut akan dirancang dalam bentuk yang kompak agar pemasangan/pembangunan serta operasinya mudah, serta diusahakan menggunakan energi sekecil mungkin.

\subsection{Pembangunan IPA-RO dan Pengujian Pengoperasian}

Setelah sistem proses, basic design dan rancangan tata letak unit-unit sistem pemroses sudah diketahui, maka IPA tersebut dapat segera dibangun. Setelah installing selesai dilaksanakan, barulah dilakukan pengujian pengoperasian alat dan analisa laboratorium hasil pengolahan air terhadap beberapa parameter sesuai dengan standar air minum yang berlaku.

\subsection{Pelatihan Pengoperasian Alat dan Sistem Manajemen}

Sebelum diserahkan kepada calon pengelola, dilakukan pelatihan pengoperasian IPA serta cara perawatan dan managemen kepada calon pengelola agar dapat beroperasi dengan baik dan berkesinambungan. Bagaimana sistem pengelolaan yang harus digunakan agar nilai investasi yang sudah ada dapat berkembang secara berarti dan berdampak positif bagi peningkatan taraf kehidupan masyarakat pedesaan tersebut.

\section{HASIL DAN PEMBAHASAN}

\subsection{Penentuan Lokasi}

Tahap kedua pelaksanaan kegiatan ini adalah telah ditentukan lokasi penempatan unit pengolahan air siap minum dengan kapasitas 10.000 meter kubik per hari. Lokasi tersebut semula direncanakan di Pulau Balang Lompo, namun karena pertimbangan lain, Pemda Pangkep meminta untuk diprioritaskan pada Pulau Pandangan yang lokasinya lebih jauh dan jarak tempuh pelayarannya bisa mencapai 5-13 jam tergantung cuaca. Lokasi Bagunan Peralatan, diusahakan dekat dengan pembangkit listrik, dan Jarak pengambilan air baku tidak lebih $25 \mathrm{~m}$ dari pelindung sekitar.

\subsection{Bangunan Pelindung Dan Sumber Air Baku}

Bangunan pelindung menggunakan bangunan pembangkit listrik yang sudah ada, dengan memodifikasi bagian dalam dan menambah lebar ruangan sedikit. Ruangan yang tersedia sekitar 2,5 meter $\times 6$ meter.

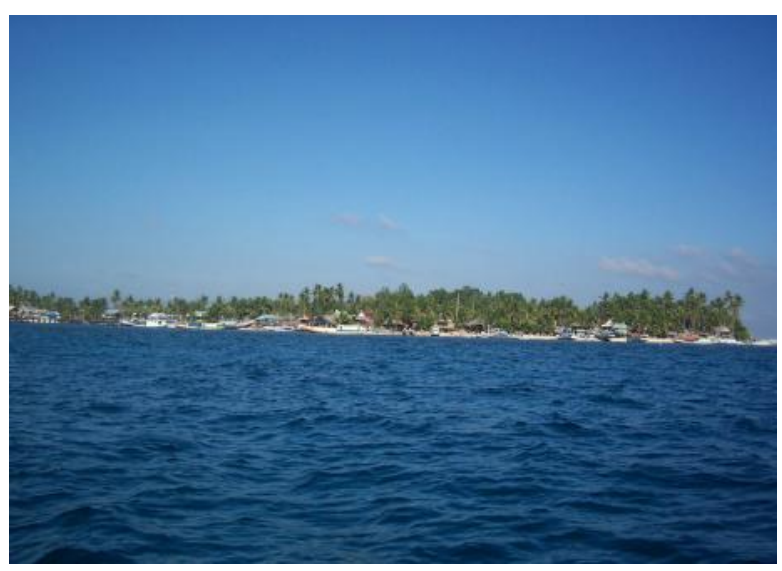

Gambar 2 : Pulau Pandangan, Kabupaten Pangkajene Kepulauan.

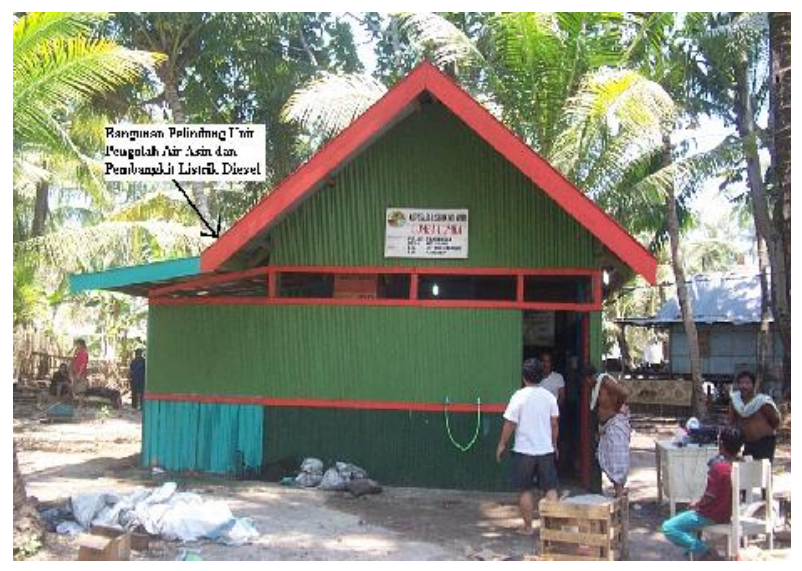

Gambar 3 : Bangunan Pelindung Instalasi Diesel Pulau Pandangan Yang Diperlebar Oleh Masyarakat Sebagai Tempat Pengolah Air Asin.

Air baku yang akan digunakan untuk pengolahan digunakan dari sumur penduduk yang berada ditengah pulau, yang airnya payau. Sebelum digunakan sumur terlebih dahulu dibersihkan dan dilakukan pengurasan dan pengujian kapasitas, untuk memastikan tidak akan terjadi kekurangan air pada sistem pada saat berjalan. 


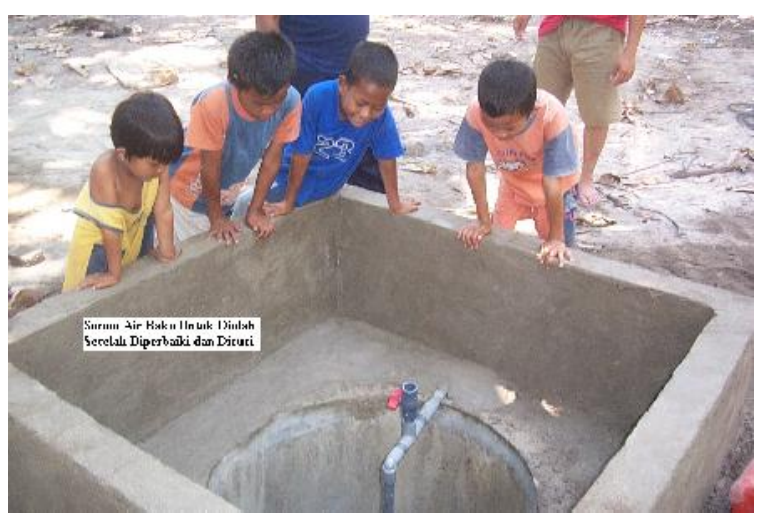

Gambar 4 : Sumur Air Baku Yang Telah diper-baiki dan Dibersihkan dan Siap Untuk Diolah Dengan Instalasi Pengolah Air Asin Menjadi Air Minum.

\subsection{Perancangan Proses}

Berdasarkan kualitas air baku yang akan diolah dibutuhkan proses, oksidasi, i, filtrasi, dan desalinasi. Air baku dipompa menggunakan pompa air baku ke reaktor tank sambil diinjeksikan $\mathrm{KmnO}_{4}$ untuk mengoksidasi Fe dan Mn serta logam-logam lainnya, oksida besi dan Mn dipisahkan pada filter pasir, selanjutnya hasil oksidasi disaring dengan media pasir silika. Selanjutnya untuk menyempurnakan proses oksidasi tersebut dilanjutkan pada filter Manganese Zeolit dan untuk menghilangkan bau dialirkan lewat activated carbon filter dan kemudian filtrasi disempurnakan dengan cartridge filter. Air yang telah melalui proses tersebut telah memenuhi syarat sebagai air bersih namun perlu dihilangkan kandungan garamnya dengan proses desalinasi osmosa balik (Reverse Osmosis). Hasil olahan setelah melewati reverse Osmosis ini telah memenuhi syarat untuk air minum. Diagram alir proses dapat dilihat pada Gambar 4.

\subsection{Spesifikasi Teknis Peralatan}

\section{a. Pompa Air baku}

$\begin{array}{ll}\text { Kapasitas } & : 50 \text { liter/menit } \\ \text { Power } & : \text { min } 250 \text { Watt } \\ \text { Pressure } & : 4-5 \text { Bars } \\ \text { Suction Head } & : 30 \mathrm{~m} \\ \text { Dischard heah } & : 30 \mathrm{~m} \\ \text { Jumlah } & : 1 \text { unit }\end{array}$

\section{b. Pompa Dosing}

$\begin{array}{ll}\text { Tipe } & : 100 / 030 \\ \text { Tekanan } & : 7 \text { Bars } \\ \text { Kapasitas } & : 4.7 \text { It/jam } \\ \text { Pump head } & : \text { SAN }\end{array}$

$\begin{array}{ll}\text { Diaphragm } & : \text { Hypalon } \\ \text { Jumlah } & : 2 \text { unit }\end{array}$

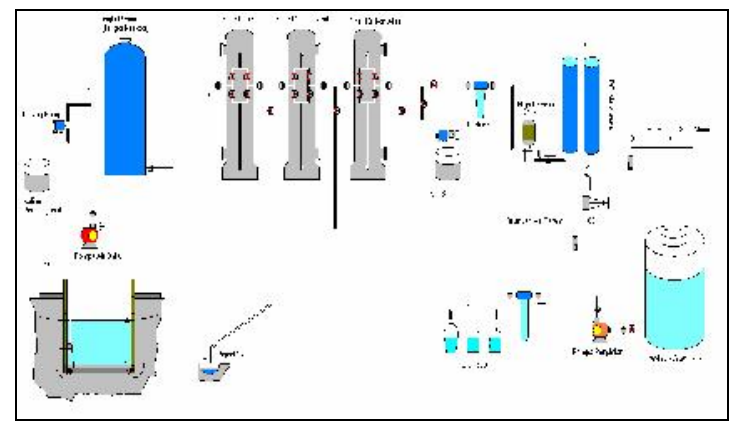

Gambar 5 : Diagram proses pengolahan air proses filtrasi dan proses reverse Osmosis.

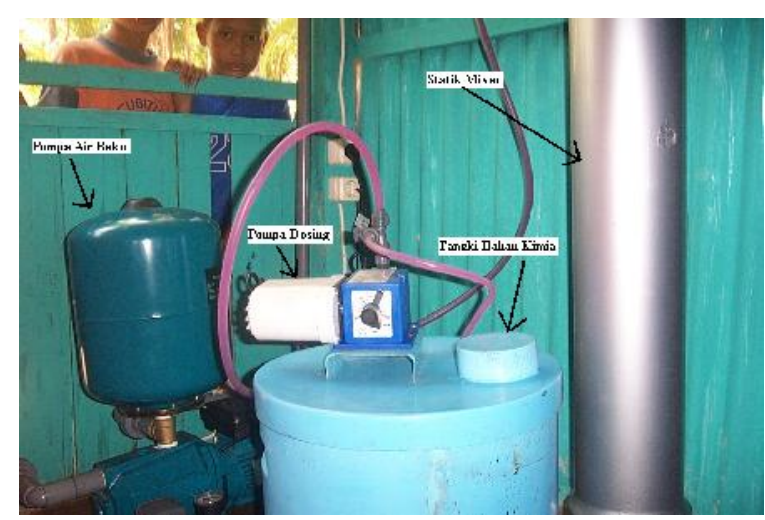

Gambar 6 : Pompa Air Baku, Pompa Dosing, Tangki Bahan Kimia dan Statik Mixer.

\section{c. Tangki Bahan Kimia}

$\begin{array}{ll}\text { Model } & : \text { BT } 502510 \\ \text { Volume } & : 25 \text { liter } \\ \text { Ukuran } & : 50 \mathrm{~cm} \times 25 \mathrm{~cm} \times 10 \mathrm{~cm} \\ \text { bahan } & : \text { FRB } \\ \text { Jumlah } & : 2 \text { unit }\end{array}$

\section{d. Filter Reaktor}

$\begin{array}{ll}\text { Model } & : \text { RT } 6312 \\ \text { Kapasitas } & : 0,5-1 \mathrm{M}^{3} / \mathrm{jam} \\ \text { Ukuran } & : 63 \mathrm{~cm} \times 120 \mathrm{~cm} \\ \text { Bahan } & : \text { PVC } \\ \text { Inlet/Outlet } & : 1 \text { “ } \\ \text { Jumlah } & : 1 \text { unit }\end{array}$

\section{e. Saringan Pasir cepat}

$\begin{array}{ll}\text { Model } & : \text { F } / \mathrm{S} 12 \\ \text { Kapasitas } & : 1.4-1.8 \mathrm{~m}^{3} / \mathrm{jam} \\ \text { Ukuran } & : \varnothing 8 \text { inchi } \times 120 \mathrm{~cm} \\ \text { bahan } & : \text { PVC }\end{array}$




$\begin{array}{ll}\text { Pipa Inlet / outlet } & : 3 / 4 \text { inch } \\ \text { Media Filter } & : \text { Pasir Silika } \\ \text { Supporting Media } & : \text { Gravel } \\ \text { Jumlah } & : 1 \text { unit }\end{array}$

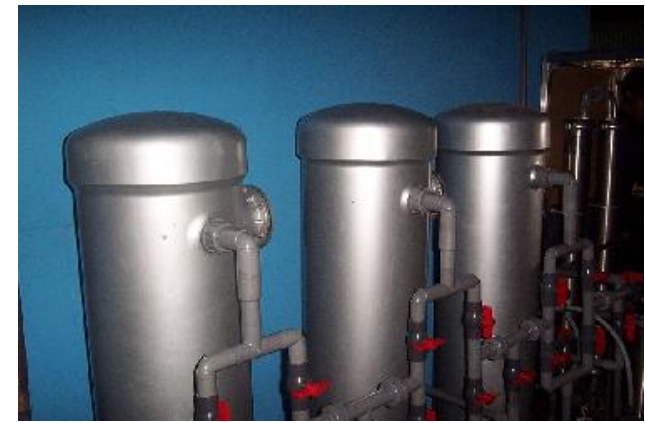

Gambar 7 : Saringan Filter Pasir Silika, Mangan Zeolit dan Pemukar Ion.

\section{f. Filter Iron Mangan}

$\begin{array}{ll}\text { Model } & : \text { FH } 12 \\ \text { Kapasitas } & : 1.4-1.8 \mathrm{m3} / \text { jam } \\ \text { Ukuran } & : \varnothing 8 \text { inchi x } 120 \mathrm{~cm} \\ \text { Bahan } & : \text { PVC } \\ \text { Pipa Inlet / outlet } & : 3 / 4 \text { inch } \\ \text { Supporting Media } & : \text { Gravel } \\ \text { Media Filter } & : \text { Manganese } \\ \text { Jumlah } & : 1 \text { unit }\end{array}$

\section{g. Penghilang Warna}

$\begin{array}{ll}\text { Model } & : \text { FC } 12 \\ \text { Kapasitas } & : 1.0-1.25 \mathrm{~m} 3 / \text { hour } \\ \text { Ukuran } & : \varnothing 8 \text { inchi x } 120 \mathrm{~cm} \\ \text { Bahan } & : \text { PVC } \\ \text { Pipa Inlet /outlet } & : 3 / 4 \text { inch } \\ \text { Supporting Media } & : \text { Gravel } \\ \text { Media Filter } & : \text { Karbon Aktif Butiran } \\ \text { Jumlah } & : 1 \text { unit }\end{array}$

\section{h. Sistem Osmosa Balik}

$\begin{array}{ll}\text { Model } & : \text { SW } 10 \mathrm{~T} \\ \text { Kapasitas } & : 10 \mathrm{~m}^{3} / \text { hari } \\ \text { Air baku } & : \text { Air Laut } \\ \text { TDS } & :<45000 \mathrm{ppm} \\ \text { Tekanan air masuk } & : 1 \mathrm{bar} \\ \text { Tekanan Operasi } & : 20-45 \text { bars } \\ \text { Temperatur Operasi: Max } 40{ }^{\circ} \mathrm{C} \\ \text { Kadar besi } & :<0.01 \mathrm{ppm} \\ \text { Kadar mangan } & :<0.01 \mathrm{ppm} \\ \text { Kadar khlorida } & :<0.01 \mathrm{ppm} \\ \text { Tipe elemen } & : \text { TFC } \\ \text { Motor } & : 2,2 \mathrm{KW} \\ \text { Kelengkapan } & \end{array}$

\footnotetext{
- Product Flow meter
}

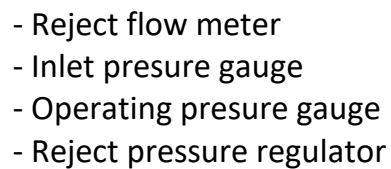

\section{i. Penampung Air Bersih}

$\begin{array}{ll}\text { Volume } & : 500 \text { Liter } \\ \text { Bahan } & : \text { FRP } \\ \text { Gate Valve } & : 3 / 4 \\ \text { Jumlah } & : 2 \text { Unit }\end{array}$

\section{j. Pompa Air Olahan/Pengisian}

$\begin{array}{ll}\text { Kapasitas } & : 25 \text { liter/menit } \\ \text { Power } & : 100 \text { Watt } \\ \text { Pressure } & : 4-5 \text { Bars }\end{array}$

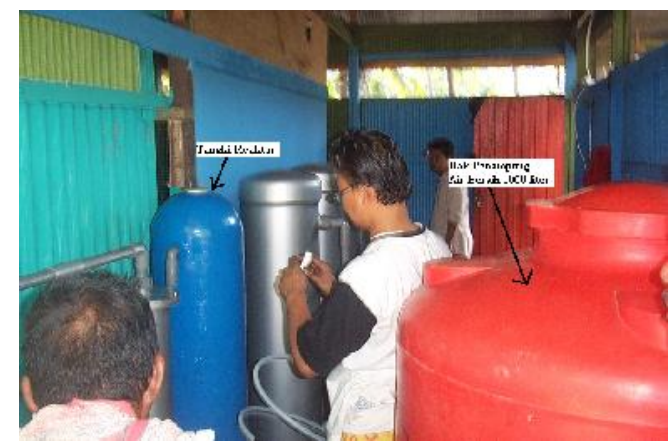

Gambar 8 : Tangki Reaktor dan Bak Penampung Air Bersih Volume 1000 liter.

\subsection{Pelatihan Dan Sosialisasi}

Secara kualitatif hasil kegiatan ini dapat meningkatkan taraf hidup masyarakat dengan adanya penyediaan air siap minum yang dijual dengan harga yang sangat murah dibandingkan dengan apabila membeli air kemasan. Selain itu dengan adanya unit alat pengolahan air langsung siap minum tersebut masyarakat tidak perlu lagi memasak air, sehingga dapat menghemat bahan bakar dan mengurangi resiko kebakaran akibat memasak air.

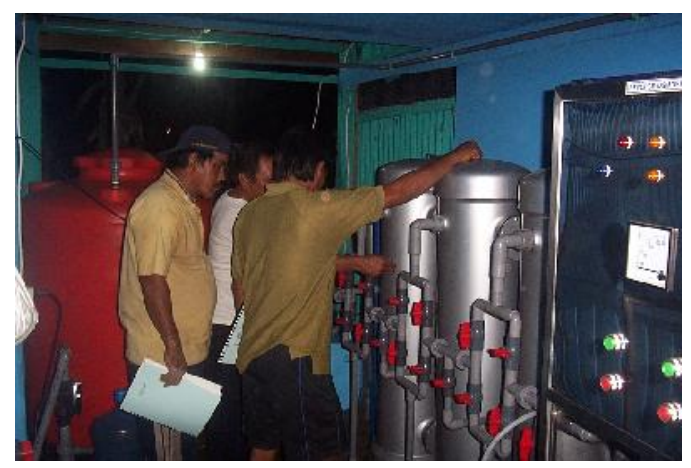

Gambar 9 : Unit Pengolah Air Sistem Osmosa Balik. 
Selain hal tersebut diatas, kegiatan tersebut merupakan pemacuan teknologi di bidang pengolahan air payau menjadi air siap minum dengan menggunakan proses filtrasi dan proses reverse osmosis yang mana teknologi tersebut belum ada sebelumnya di Pulau Pandangan.

Hasil kegiatan ini berupa satu unit percontohan instalasi pengolahan air laut menjadi air siap minum dengan kapasitas 10.000 liter per hari. Unit instalsi tersebut dikelola oleh masyarakat Pulau Pandangan dan air hasil olahan akan dijual masyarakat dengan harga murah, berkisar Rp. 500 Rp. 1000,-, dalam bentuk botol galon 20 liter. Hasil penjualan air tersebut digunakan untuk biaya operasional dan perawatan.

\subsection{Kualitas Air Hasil Olahan}

Proses pengolahan air dengan osmosa balik, berhasil mengolah air laut menjadi air tawar siap minum. TDS air laut berkisar 33.000 ppm (asin) dan dapat diolah sampai 300 ppm (tawar), dengan debit berkisar 400 - 450 liter/jam. Untuk masyarakat pulau kadar TDS 750 ppm masih berasa tawar, berbeda dengan orang daratan yang biasa minum air kemasan dengan TDS berkisar 80 sd 120 ppm. Kemampuan penyaringan membran osmosa balik adalah seperseribumikron, dan mampu menyaring bakteri.

Permukaan air sumur gali dapat naik dan turun, karena dipengaruhi oleh pasang dan surut, pada saat surut air lebih tawar (TDS Rendah), tetapi pada saat pasang air sumur akan tambah rasa asinnya. Walapun kualitas airnya naik turun, air hasil olahannya masih dalam kisaran yang aman untuk diminum dan masih terasa tawar.

\subsection{Permasalahan Dan Hambatan}

Dalam pelaksanaan kegiatan ini, untuk porsi BPPT secara teknis maupun administrasi tidak ada hambatan. Pengadaan bahan, peralatan dan mesin secara administrasi ditempuh sesuai dengan aturan yang berlaku dan kondisi barang dalam keadaan baik serta memenuhi persyaratan maupun spesifikasi yang ditentukan. Masalah non teknis yang lain, yakni kegiatan ini hanya berjalan satu tahun sehingga, pembinaan mangement terhadap pengelola mitra kerja serta pembinaan teknis terbatas hanya pada tahun anggaran berjalan.

Pada umumnya lokasi tempat penempatan peralatan teknologi osmosa balik terletak di pulau yang jauh dari sumber air tawar, sarana transportasi masih susah dan waktu tempuhnya cukup lama, sehingga apabila terjadi kerusakan masalah suku cadang tidak bisa cepat di atasi, oleh karena itu pada saat pemasangan sediakan suku cadang dalam jumlah cukup, terutama bagian yang sering diganti, seperti cartridge filter.

\section{KESIMPULAN}

- Teknologi Osmosa balik dapat digunakan untuk mengatasi permasalahan air bersih di pulau-pulau terpencil ;

- Masyarakat mampu membiayai operasional peralatan dengan cara membeli air hasil olahan ;

- Pemerintah perlu melakukan subsidi untuk implementasi teknologi pengolahan air sistem osmosa balik di pulau-pulau terpencil ;

- Penyerapan teknologi pengolahan air sistem osmosa balik layak diterapkan pada daerah yang sulit dan tidak ada air tawar ;

- Pelibatan masyarakat sangat diperlukan untuk membangkitkan rasa memiliki dan kemauan untuk merawat peralatan yang ada.

\section{DAFTAR PUSTAKA}

- Arie, H, 1989, Teknologi Pengolah Air Asin Reverse Osmosis dan prospeknya di Indonesia, Proceeding Seminar Teknologi Pengolahan Air, Krakatau Steel, Cilegon.

- Arie, H, Dharmawan dan Komariah, 1988, Studi Pengkajian Teknologi Reverse osmosis Sistem X Flow RO-01, Direktorat Pengkajian Sistem, Deputi Bidang Analisis Sistem, BPPT, Jakarta.

- Arie, H, Nusa, I.D., Nugro, R., dan Haryoto, I., 1996, Studi Penerapan Teknologi Pengolahan Air Payau Kapasitas 10 m3/hari, Direktorat Pengkajian Sistem Industri Jasa, Deputi Bidang Analisis Sistem, BPPT, Jakarta.

- Arie, H., Nusa, I.D, Nugro, R., dan Haryoto, I., 1996, Studi Kelayakan Teknis dan Ekonomis Unit Pengolah Air Sistem Reverse Osmosis Kapasitas $500 \mathrm{~m} 3 /$ hari Untuk perusahaan minyak lepas pantai, P.T. Paramita Binasarana, Jakarta.

- Asaoka Tadatomo, "Yousui Haisui Shori Gijutsu ", Tokyo, 1973.

- Benefiled, L.D., Judkins, J.F., and Weand, B.L., "Process Chemistry For Water And Waste Treatment", Prentice-Hall, Inc., Englewood, 1982.

- Bunce, N.J. , 1993, Intruduction to Environmental Chemistry, Wuerz Publishing Ltd, Winnipeg, Canada.

- Fair, G.M., Geyer, J.C., AND Okun, D.A., " Element Of Water Supply And Waste Water Disposal ", Second Edition, John Wiley And Sons, New York, 1971.

- Hamer, M. J., " Water And Waste water Technology ", Second Edition, John Wiley And Sons, New York, 1986. 
- Peavy, H.S., Rowe, D.R, AND Tchobanoglous, S.G., "Environmental Engineering ", Mc Graw-Hill Book Company, Singapore, 1986.

- Sasakura, 1995, Desalination Technology and Its Aplication, P.T. Sasakura Indonesia, Jakarta.
- Tatsumi Iwao, "Water Work Engineering (JOSUI KOGAKU) ", Japanese Edition, Tokyo, 1971.

- Viessman W,JR., "Water Supply And Pollution Control ", fourth edition, Harper and Ror Publisher, New york, 1985. 